\title{
Carbonate and carbamate derivatives of 4-demethylpenclomedine as novel anticancer agents
}

\author{
Lee Roy Morgan · Robert F. Struck · William R. Waud • \\ Blaise LeBlanc · Andrew H. Rodgers · Branko S. Jursic
}

Received: 27 July 2008 / Accepted: 9 January 2009 / Published online: 3 March 2009

(C) The Author(s) 2009. This article is published with open access at Springerlink.com

\begin{abstract}
Purpose The purpose of this investigation was to synthesize a series of carbonate and carbamate derivatives of 4-demethylpenclomedine (DM-PEN), the major plasma non-toxic metabolite of penclomedine (PEN) seen in patients. DM-PEN has been observed to be an active antitumor agent in mouse human xenograft tumor models and non-neurotoxic in a rat model, however, activity in intracranially implanted human glioma xenograft models have not been reported. The major goal was to identify derivatives that are active in brain tumors.

Methods Derivatives were prepared from DM-PEN and evaluated in vivo against human U251 glioblastoma, D54 glioblastoma and MX-1 breast tumor xenografts and mammary tumor $16 / \mathrm{C}$ that were implanted in the mammary fat pad or intracranially (IC).

Results Carbonate and carbamate derivatives were found to be superior to DM-PEN against IC growing human glioblastoma xenografts.

Conclusion The activity of the carbonates and carbamates against human tumor xenografts in vivo suggests consideration
\end{abstract}

L. R. Morgan $(\bowtie) \cdot$ B. LeBlanc · A. H. Rodgers

DEKK-TEC, Inc., New Orleans, LA, USA

e-mail:1rm1579@aol.com

R. F. Struck

CancerMedica, LLC, Birmingham, AL, USA

W. R. Waud

Department of Chemotherapy,

Southern Research Institute, Birmingham, AL, USA

B. S. Jursic

Department of Chemistry,

University of New Orleans, New Orleans, LA, USA of these two series of derivatives of DM-PEN for clinical development.

Keywords Penclomedine .

4-Demethylcholesteryloxycarbonylpenclomedine .

Antitumor evaluation in vivo $\cdot$ Human tumor xenografts

\section{Introduction}

Penclomedine (PEN) has been evaluated in phase I clinical trials at Johns Hopkins University Oncology Center, the University of Wisconsin Comprehensive Cancer Center and Western General Hospital in Edinburgh [1-5] for possible use in the treatment of breast cancer and gliomas. This was based on activity against human breast tumor xenografts and experimental mammary tumor models, and against tumor xenografts growing intracranially (IC) in mice $[6,7]$. In all of these clinical trials, dose-limiting neurotoxicity was observed after both intravenous and oral administration and was related to peak plasma levels of PEN [1-4]. 4-Demethyl-penclomedine (DM-PEN) was identified as the major plasma metabolite in patients and rodents [4, 8-10], and neuroanatomic studies with PEN and DM-PEN in rats revealed cerebellar damage only in the PEN-treated group [11, 12].

These observations led to the evaluation of DM-PEN as therapy versus intracranially implanted and growing glioma xenograft models $[10,13]$. DM-PEN did demonstrate an improved percentage ILS, but no complete responses were noted when administered intraperitoneally (IP) to mice bearing intracranially (IC) implanted human U251 gliomas and MX-1 breast cancer xenografts [14]. A series of acyl derivatives of DM-PEN have been synthesized and evaluated against several human tumor xenografts including the 
MX-1 tumor, and murine P388 leukemia, revealing potent activity [15]. Subsequently, a series of thiolo-, thiono- and dithiocarbonate and thiocarbamate analogs of 4-DM-PEN have been synthesized and evaluated in human MX-1 breast tumor xenografts implanted in the mammary fat pad. Antitumor activities were comparable to the acyl-DM-PEN derivatives [16]. The results of the latter study have prompted the description of the synthesis and antitumor profiles for a series of carbonate and carbamate analogs, which have been compared with IC implanted MX-1 breast tumor, U251 and D54 human glioblastoma multiforme xenografts, revealing potent activity [16]. The presence of a high-energy carbonate linker in some of the analogs may be an influencing factor in the activities seen for this group in view of the energy requirements for gliomas and CNSassociated neoplasia [17]. The present anticancer data are presented in support of the clinical development of a cholesterol carbonate derivative of DM-PEN-DM-CHOCPEN.

\section{Materials and methods}

4-Demethyl-penclomedine was prepared by a modification of the reported method as a white, crystalline solid, which was characterized by mass spectral, NMR and elemental analysis [10].

A general experimental procedure for the preparation of the carbonate and carbamate derivatives of DM-PEN was as follows: DM-PEN $(1 \mathrm{~g})$ in $15 \mathrm{ml}$ dry dichloromethane was treated with $0.5 \mathrm{ml}$ triethylamine followed by one equivalent of a chlorocarbonate or a carbamoyl chloride, respectively (obtained from Sigma-Aldrich), in $5 \mathrm{ml}$ dry dichloromethane, added dropwise with stirring at $-78^{\circ} \mathrm{C}$. The reaction mixture was stirred for $3 \mathrm{~h}$ at $-78^{\circ} \mathrm{C}$ and the solvent removed by evaporation in vacuo. The residue was triturated with $5 \mathrm{ml}$ acetone and filtered to remove triethylamine hydrochloride. The acetone filtrate was concentrated to $1 \mathrm{ml}$ and separated by preparative thin layer chromatography (TLC) on silica gel in a hexane:methylene chloride solvent $(1: 1 \mathrm{v} / \mathrm{v})$. The major UV-visible band was collected and eluted with THF, and the solvent evaporated to dryness in vacuo. The residue was characterized by mass spectral (FABMS), NMR (H) and elemental (CHN) analysis. If the product was not analytically pure, it was separated again by preparative TLC for subsequent re-analysis. Most products did not require a second TLC purification step, and a high yield was obtained. Characterization was provided by mass spectrometry, which reveals the appropriate mass number +1 corresponding to the expected structure, and TLC, which yields a single UV-visible component.

Chemical characterizations of the derivatives are available upon request (LRM1579@aol.com).DM-CHOC-PEN has been selected for clinical trials; m.p., NMR (varian unity) and CHN elemental analyses are presented below and MS (Perkin Elmer Series 200) in Fig. 1: m.p. 171$172^{\circ} \mathrm{C}$ ); anal. $\mathrm{C}_{35} \mathrm{H}_{48} \mathrm{Cl}_{5} \mathrm{NO}_{4}$ : calc. $\mathrm{C}, 58.9, \mathrm{H}, 6.7, \mathrm{~N}, 1.9$; found: $58.7, \mathrm{H}, 6.9, \mathrm{~N}, 1.8 ;{ }^{13} \mathrm{C}-\mathrm{NMR}(400 \mathrm{MHz}$, varian unity, $\left.\mathrm{CDCl}_{3}\right) \delta 155.568,153.879,149.261,147.659,138.614$, 123.545, 117.544, 114.879, 95.622, 80.831, 56.673, 56.156, 55.472, 49.980, 42.341, 39.726, 39.544, 37.665, 36.769, $36.551,36.216,35.815,31.933,31.860,28.255,28.044$, $27.469,24.315,23.878,22.859,22.611,21.104,19.312$, 18.773 , and $11.920 \mathrm{ppm} ;{ }^{1} \mathrm{H}-\mathrm{NMR}(400 \mathrm{MHz}$, varian unity: $\sigma 5.428(1 \mathrm{H}, d, J=6.4 \mathrm{~Hz}), 4.629(1 \mathrm{H}, \mathrm{m}), 4.113(3 \mathrm{H}, \mathrm{s})$, $2.516(2 \mathrm{H}, \mathrm{m})$, and between 0.6 and $2.1 \mathrm{ppm}$ multiple signals for all other hydrogen.

\section{Antitumor evaluation in vivo}

Antitumor evaluations were conducted as described previously $[10,15]$. Athymic NCr-nu/nu and B6C3F1 mice were obtained from various suppliers under contract with NCI and were housed in sterile, filter-capped microisolator cages in a barrier facility at SRI. Human tumors were obtained from the NCI Tumor Repository (Frederick, MD, USA). For IP injection into mice, DM-PEN and the derivatives were prepared in a vehicle of 3\% Klucel (hydroxypropyl cellulose) and $1.92 \%$ Tween 80 in saline, as a smooth suspension. MX-1 and 16/C breast tumor fragments (30$40 \mathrm{mg}$ ) from in vivo passage were implanted SC into the mammary fat pad of the mice. For IC implants, mice were sedated with ketamine, placed in a Kopf stereotaxic frame, over the dorsum of the skull, skin and calvarium bone were reflected under sterile conditions and $0.03 \mathrm{ml}$ of MX-1 breast cancer, or U251 or D54 human glioma brei (containing $10^{6}$ cells) injected into the right hemisphere of the mice via a 0.25 inch 25 -gauge stainless steel needle with angling toward the center of the brain. Bone chips and skin clips were placed in the brain cavity/skin to control bleeding and allow healing. Morbidity was rare and tumor take-rate was typically ca. $100 \%$.

Treatment of groups of five mice each was initiated when the SC tumors reached approximately $300 \mathrm{mg}$ in subcutaneous (SC) mass size (or on the 5th day after IC implantation) and was continued for 5 days or Q4 days $\times 3$. Each SC growing breast tumor was measured by caliper in two dimensions twice weekly and converted to

Fig. 1 Where: $\mathrm{PEN}, \mathrm{R}=\mathrm{CH}_{3}$ and DM-PEN, $\mathrm{R}=\mathrm{H}$<smiles>COc1nc(C(Cl)(Cl)Cl)c(Cl)c(O)c1Cl</smiles> 
Table 1 Activity of derivatives of DM-PEN versus intracerebrally (IC) implanted U251 glioblastoma xenograft tumors in mice

\begin{tabular}{lllll}
\hline Drug & Dose $(\mathrm{mg} / \mathrm{kg})$ & Schedule/route & $\begin{array}{l}\text { Percentage increase } \\
\text { life span (\% ILS) }\end{array}$ & $\begin{array}{l}\text { Percentage long term } \\
\text { survivors (\% LTS) }\end{array}$ \\
\hline Control & Vehicle & Q1D $\times 5 ;$ IP & 0 & $0 / 5$ \\
DM-PEN & $90(>$ is toxic) & $\sqrt{ }$ & +17 & $0 / 5$ \\
DM-BOC-PEN & 90 & $\sqrt{ }$ & +15 & $0 / 5$ \\
DM-NBOC-PEN & 90 & $\sqrt{ }$ & +27 & $0 / 5$ \\
DM-CHOC-PEN & 135 & $\sqrt{ }$ & +54 & $20(1 / 5 \mathrm{CR})$ \\
DM-COC-PEN & 90 & $\sqrt{ }$ & +4 & $0 / 5$ \\
DM-acetyl-PEN & 90 & $\sqrt{ }$ & +38 & $0 / 5$ \\
(DM-PEN) $)_{2}-\mathrm{CO}$ & 135 & $\sqrt{ }$ & +15 & $0 / 5$ \\
DM-GLUC-PEN & 135 & $\sqrt{ }$ & +4 & $0 / 5$ \\
DM-DMC-PEN & 135 & $\sqrt{ }$ & +21 & $0 / 5$ \\
BCNU & $9(>$ is toxic) & QD $\times 5 ;$ PO & $33-+92$ & $20(1 / 5 \mathrm{CR})$ \\
TMZ & 120 & +59 & $20(1 / 5 \mathrm{CR})$ \\
\hline
\end{tabular}

${ }^{a}$ An acyl derivative-4-demethyl-tetramethylglucuronyl-PEN

Implant: $10^{6}$ cells IC; treatment route: intraperitoneal (-5 days post IC implant); schedule: $\mathrm{q} 1 \mathrm{~d} \times 5 \mathrm{~d}$; species: athymic $\mathrm{NCr} / \mathrm{nu}$ mice-adult, female, Charles River 5-mice/group

Table 2 Activity of carbonate derivatives of DM-PEN versus intracerebrally (IC) implanted D54 glioblastoma xenograft tumors in mice

\begin{tabular}{lllll}
\hline Drug & Dose $(\mathrm{mg} / \mathrm{kg})$ & Schedule/route & $\begin{array}{l}\text { Percentage increase } \\
\text { life span (\% ILS) }\end{array}$ & $\begin{array}{l}\text { Percentage long term } \\
\text { survivors (\% LTS) }\end{array}$ \\
\hline Control & Vehicle & QD $\times 5 ;$ IP & 0 & $0 / 10$ \\
DM-BOC-PEN & 135 & $\sqrt{ }$ & +23 & $0 / 5$ \\
DM-CHOC-PEN & 200 & $\sqrt{ }$ & +53 & $1 / 6$ \\
DM-NBOC-PEN & 200 & $\sqrt{ }$ & 33 & $0 / 5$ \\
BCNU & $9(>$ is toxic) & $\sqrt{ }$ & 33 & $0 / 5$ \\
\hline
\end{tabular}

Implant: $10^{6}$ cells IC; treatment route: intraperitoneal (-5 days post IC implant); schedule: q1d $\times 5 \mathrm{~d}$; species: athymic $\mathrm{NCr} / \mathrm{nu}$ mice-adult, female, Charles River 5-mice/group

tumor mass. IC antitumor activity was assessed on the basis of tumor growth delay in comparison to a vehicle-treated control, tumor regressions (partial and complete), and tumor-free survivors (documented at autopsy). Experiments were terminated when the control tumors attained a size of $1 \mathrm{~g}$ (or if animals demonstrated morbidity) which is typically 57-61 days. Mice were monitored daily for survival and morbidity symptoms. Antitumor activity was assessed on the basis of the percentage increase in lifespan (\% ILS), long-term survivors and presence of tumor, in comparison to vehicle-treated controls. All animals were examined for degree of tumor involvement at the time of death. The \% ILS refers to the median day of death or sacrifice due to morbidity for treated versus controls; excluding long-term survivors (\% LTS) - animals with complete responses and normal activity at termination of the study. The presence of a plus (+) before the \% ILS indicates animals still alive and without morbidity at the time of study termination. BCNU was used as a positive control (IP administration). Temozolamide (TMZ, Temodar) was included (PO administration) as a control in the U251 glioma studies. DM-acetyl-PEN, which is not a carbonate or carbamate was also included in the U251 studies (15).

Multiple doses of each derivative were evaluated in each tumor model referenced in Tables 1, 2,3,4 and 5. Doses selected in Tables 1, 2,3,4 and 5 were for the best response in that model. Animals bearing different tumors seemed to tolerate varying concentrations of derivatives, e.g. DM-CHOC-PEN and DM-BOC-PEN.

\section{Results}

Figures 2 and 3 show the structures, MS and yields of the carbonate and carbamate derivatives of DM-PEN prepared as described in "Materials and methods". The vehicle for all the derivatives was as described in the "Materials and methods", and tolerated well, however, in the human studies a soybean oil/egg yolk lecithin based-vehicle will be used to deliver the derivatives as an emulsion.

The derivatives were evaluated against five separate mouse tumor models-(Tables 1, 2, 3, 4, 5). A range of IP 
Table 3 Activity of DM-CHOC-PEN versus intracerebrally (IC) implanted MX-1 breast cancer xenograft in mice

\begin{tabular}{lllll}
\hline Drug & Dose (mg/kg) & Schedule/route & $\begin{array}{l}\text { Percentage increase } \\
\text { life span (\% ILS) }\end{array}$ & $\begin{array}{l}\text { Percentage long term } \\
\text { survivors (\% LTS) }\end{array}$ \\
\hline Control & Vehicle & QD $\times 5 ;$ IP & 0 & $0 / 12$ \\
DM-CHOC-PEN & 25 & $\sqrt{ }$ & +6 to +20 & $16(1 / 6 \mathrm{CR})$ \\
DM-PEN & 90 & $\sqrt{ }$ & 60 & $0 / 5 \mathrm{CR}$ \\
PEN & 90 & $\sqrt{ }$ & 88 & $0 / 5 \mathrm{CR}$ \\
BCNU & 6 & $\sqrt{ }$ & 33 & $0 / 5 \mathrm{CR}$ \\
\hline
\end{tabular}

Implant: $10^{6}$ cells IC; treatment route: intraperitoneal (-5 days post IC implant); schedule: $q 1 \mathrm{~d} \times 5 \mathrm{~d}$; species: athymic $\mathrm{NCr} / \mathrm{nu}$ mice—adult, female, Charles River 5-mice/group

Table 4 Activities of carbonates of DM-PEN versus intramammary fat pad (SC) implanted 16/C mammary tumor in mice

\begin{tabular}{lllll}
\hline Drug & Dose $(\mathrm{mg} / \mathrm{kg})$ & $\begin{array}{l}\text { Schedule/ } \\
\text { route }\end{array}$ & $\begin{array}{l}\text { Disease } \\
\text { free }\end{array}$ & $\begin{array}{l}\text { Days } \\
\text { delay }\end{array}$ \\
\hline Control & Vehicle & Q4D × 3; IP & 0 & 0 \\
DM-OOC-PEN & $90(>$ is toxic) & $\sqrt{ }$ & 0 & 1.7 \\
DM-BOC-PEN & 90 & $\sqrt{ }$ & 0 & 2.2 \\
DM-NBOC-PEN & 200 & $\sqrt{ }$ & 0 & 1.7 \\
DM-CHOC-PEN & 135 & $\sqrt{ }$ & 0 & 2.8 \\
DM-POC-PEN & 90 & $\sqrt{ }$ & 0 & -0.9 \\
DM-CFBOC-PEN & 90 & $\sqrt{ }$ & 0 & 1.9 \\
DM-EOC-PEN & 200 & $\sqrt{ }$ & 0 & 2.3 \\
\hline
\end{tabular}

Implant: $10^{6}$ cells SC in mammary fat pad; treatment: initiated-when tumor mass $\sim 300 \mathrm{mg}$ and terminated at $\sim 1 \mathrm{~g}$ or 57-61 days); species: B6C3F1 - adult/female, Charles River 5-6 mice/group

Table 5 Activity of derivatives of DM-PEN versus subcutaneously (SC) implanted MX-1 breast cancer xenografts in mice

\begin{tabular}{lllll}
\hline Drug & $\begin{array}{l}\text { Dose } \\
(\mathrm{mg} / \mathrm{kg})\end{array}$ & $\begin{array}{l}\text { Schedule/ } \\
\text { route }\end{array}$ & $\begin{array}{l}\text { Growth } \\
\text { delay } \\
(\mathrm{T}-\mathrm{C})\end{array}$ & $\begin{array}{l}\text { Tumor-free } \\
\text { survivors }\end{array}$ \\
\hline Control & Vehicle & $\mathrm{Q} 1 \mathrm{D} \times 5$; IP & 0 & $0 / 5$ \\
DM-PEN & 135 & $\sqrt{ }$ & $>38$ & $5 / 5$ \\
PEN & 90 & $\sqrt{ }$ & $>41$ & $5 / 5$ \\
DM-MOC-PEN & 90 & $\sqrt{ }$ & $>41$ & $1 / 5$ \\
DM-acetyl-PEN & 90 & $\sqrt{ }$ & $>41$ & $5 / 5$ \\
DM-BOC-PEN & 90 & $\sqrt{ }$ & $>34$ & $1 / 5$ \\
DM-DMC-PEN & 135 & $\sqrt{ }$ & $>41$ & $5 / 5$ \\
\hline
\end{tabular}

Implant: $10^{6}$ cells SC in mammary fat pad; treatment: initiated-when tumor mass $\sim 300 \mathrm{mg}$ and terminated at $\sim 1 \mathrm{~g}$ or 57-61 days; schedule: q1d $\times 5 \mathrm{~d}$; species: athymic $\mathrm{NCr} / \mathrm{nu}$ mice-adult, female, Charles River 5-mice/group

dosages ranging from 25 to $300 \mathrm{mg} / \mathrm{kg}$ per dose was used, including the maximum tolerated dose, when known. Several of the carbonate derivatives yielded complete responses and produced tumor-free survivors. The derivatives were tested (in the model available) as they were synthesized. Not all derivatives were screened versus the same tumor model.
The cholesterol carbonate derivative, DM-CHOC-PEN, was evaluated against intracranially implanted U251 human glioblastoma xenograft and was observed to have improved activity versus the other derivatives [15]. DM-CHOC-PEN was also evaluated against intracranially implanted D54 human glioblastoma multiforme, a highly resistant brain tumor, and yielded a 1/6 complete response, modest but improved over that observed with BCNU, the current drug of choice for clinical treatment of malignant gliomas, the major brain tumor in the USA. TMZ was included in the U251 glioma studies. Comparison of its activity with other carbonates versus BCNU and TMZ is available in Table 1. DM-CHOC-PEN in a side-by-side experiment versus DM-PEN revealed a 54\% increase in life span (ILS), with $20 \%$ complete response versus $17 \%$ and no long-term survivors for DM-PEN, respectively.

DM-CHOC-PEN demonstrated activities not only in the U251 glioma model but also in D54 glioma, MX-1 and 16/ C breast tumor models, (Tables 2, 3,4). These anticancer activities continue to support DM-CHOC-PEN as a significant candidate for clinical studies.

The antitumor activities for the carbamates are shown in Tables 1 and 5. Against SC growing MX-1 human mammary tumor xenograft, a dimethyl carbamate derivative, DM-DMC-PEN, was observed to be equivalent to DMPEN in antitumor activity. In the U251 glioma model activity for DM-DMC-PEN was modest (not as good as DM-CHOC-PEN), but still improved versus DM-PEN.

Statistical considerations: DM-CHOC-PEN was the only derivative that consistently produced complete responses in the U251 glioma model, satisfying our goal to develop agents for the treatment of brain tumors.

\section{Discussion}

Earlier studies demonstrated that DM-PEN was comparably active to PEN against MX-1 human tumor xenografts but that it lacked the neurotoxicity of PEN in a rat model [10]. This observation identified it as a reasonable candidate for derivatization as a means of producing structures 
Fig. 2 Carbonate analogs synthesized (MS values)
DM-FOC-PEN $\mathrm{R}=\alpha$-fluorobenzyl $(\mathrm{M}+\mathrm{H})^{+} 461$; Yield: $39 \%$ DM-COC-PEN $\mathrm{R}=\alpha$-chlorobenzyl $(\mathrm{M}+\mathrm{H})^{+} 478$; Yield: $65 \%$ DM-BOC-PEN $\mathrm{R}=$ benzyl $(\mathrm{M}+\mathrm{H})^{+} 444$; Yield: $70 \%$ DM-CHOC-PEN $\mathrm{R}=$ cholesteryl $(\mathrm{M}+\mathrm{H})^{+} 724$; Yield: $83 \%$ DM-EOC-PEN $\mathrm{R}=$ ethyl $(\mathrm{M}+\mathrm{H})^{+} 382$; Yield: $80 \%$ DM-NBOC-PEN $\quad \mathrm{R}=p$-nitrobenzyl $(\mathrm{M}+\mathrm{H})^{+} 490$; Yield: $75 \%$ DM-NPOC-PEN $\mathrm{R}=p$-nitrophenyl $(\mathrm{M}+\mathrm{H})^{+} 476$; Yield: $85 \%$ DM-OOC-PEN $\mathrm{R}=n$-octyl $(\mathrm{M}+\mathrm{H})^{+} 466$; ; Yield: $72 \%$ DM-POC-PEN $\mathrm{R}=$ phenyl $(\mathrm{M}+\mathrm{H})^{+} 430$; Yield: $69 \%$ DM-MOC-PEN $\mathrm{R}=$ methyl $(\mathrm{M}+\mathrm{H})^{+} 368$; Yield: $65 \%$ $(\text { DM-PEN })_{2}$-CO R = DM-PEN $(\mathrm{M}+\mathrm{H})^{+}$620; Yield: $52 \%$
Fig. 3 Carbamate analogs synthesized (MS values)

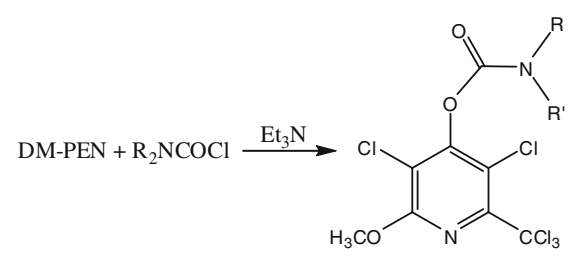

DM-DMC-PEN $\quad \mathrm{R}=\mathrm{R}^{\prime}=$ methyl $(\mathrm{M}+\mathrm{H})^{+} 381$; Yield: $50 \%$ DM-MNC-PEN $\quad \mathrm{R}=\mathrm{R}^{\prime}=N$-morpholinyl $(\mathrm{M}+\mathrm{H})^{+} 423$; Yield: $62 \%$ DM-MPC-PEN $\mathrm{R}=$ methyl, $\mathrm{R}^{\prime}=$ phenyl $(\mathrm{M}+\mathrm{H})^{+} 443$; Yield: $57 \%$ DM-DPC-PEN $\mathrm{R}=\mathrm{R}^{\prime}=$ phenyl $(\mathrm{M}+\mathrm{H})^{+}$505; Yield: $70 \%$ with increased, broad-spectrum antitumor activity in vivo and with diminished toxicity. Synthesis of a series of acyl derivatives was the first attempt to achieve this goal, and success was indicated by the improved activity against MX-1 human breast tumor xenografts implanted subcutaneously or intracranially, most notably in the latter model [15].

As a logical extension of this effort, the present series of carbonate and carbamate derivatives of DM-PEN have been prepared by reaction of DM-PEN with the appropriate chlorocarbonate or carbamoyl chloride. Evaluation of several derivatives of the series against intracranially implanted human gliomas-U251 and D54-and orthotopically implanted MX-1 breast cancer, indicated curative activity for the carbonates and carbamates. The observed reduced activity for DM-PEN in IC implanted gliomas is consistent with it being a polar metabolite of PEN and either rapidly cleared or unable to penetrate the blood-brain barrier. Thus, the polar nature of the product could prevent it from crossing the blood-brain barrier and cell membranes [14].

A major concern for any of the 4-demethylpenclomedine (PEN) derivatives is the possibility of neurotoxicity. PEN was removed from clinical development as a potential drug for treating gliomas and breast cancer because of its doselimiting neurotoxicity. Consequently, DM-CHOC-PEN was evaluated simultaneously versus PEN in a behavioral test of neurotoxicity and was observed to be non-neurotoxic, as indicated by the absence of production of tremors in the DM-CHOC-PEN group in comparison to the PEN group [12, 14]. No observed weight loss or neurotoxicity (swaying, staggering, seizure activities) was associated with the DM-CHOC-PEN treatments. The Morris water maze test results revealed an absence of impaired learning/ memory versus PEN [14]. These studies will also be included in a preclinical pharmacology and toxicology paper in preparation [20].
DM-CHOC-PEN is one of the most active DM-PEN derivatives in the present series versus IC implanted human glioblastoma and breast cancer xenografts and demonstrated complete responses in both U251 and D54 glioma xenograft models. The molecule possesses several interesting moieties/properties: a high free energy carbonate OCO-O moiety, a lipophilic cholesteryl moiety and a highly electrophilic trichloromethane moiety capable of alkylating nucleophilic sites [14].

A non-classical carbonium ion alkylating mechanism is proposed for DM-CHOC-PEN's anticancer activities in Fig. 4. The scheme describes a dual free radical/carbonium ion DNA cross-linking mechanism with tumor DNA in the major groove via $\mathrm{N}^{7}$-guanine resulting in a $\mathrm{G}-\mathrm{X}-\mathrm{C}$ crosslinking sequence [14]. A bimolecular coupled product (via the trichloromethylene group) has been identified as the major microsomal metabolite of PEN [10, 14]. The trichloromethylene group is thought to be needed, since a dichloromethylene analog of $\mathrm{PEN}$ is not active [does not react with 4-( $p$-nitrobenzyl)pyridine (NBP)] (Struck, personnel communication). No other modifications of the moiety have been studied.

This is in contrast to the free radical and hepatic activation schemes proposed for PEN and other derivatives [14, 17]. DM-CHOC-PEN is active in vitro versus glioma and breast cancer cells and does not require prior activation for anticancer effectiveness; thus further support for Fig. 4 [17, 19, 20]. The presence of a lipophilic cholesteryl moiety in DM-CHOC-PEN may potentiate its penetration of the central nervous system. DMCHOC-PEN has been extracted from U251 glioma tissue which was dissected from the brains of mice that had received IP administered DM-CHOC-PEN post IC tumor cell implantation. The surrounding normal tissue was negative for drug $[17,20]$. Thus additional support for speculations on DM-CHOC-PEN's ability to cross the 
<smiles>COc1nc(C(F)(F)Cl)c(Cl)c(OC=O)c1Cl</smiles>

DM-CHOC-PEN<smiles>CC1C(=O)C(Cl)=C(Cl)N=C1Cl</smiles>

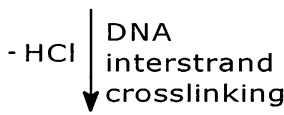<smiles>CC1C(=O)C(Cl)=C(Cl)N=C1O</smiles>

transported to tumor cells $-\mathrm{Cl}^{-}$

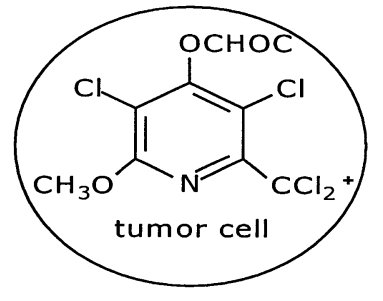

carbonylated carbonium ion

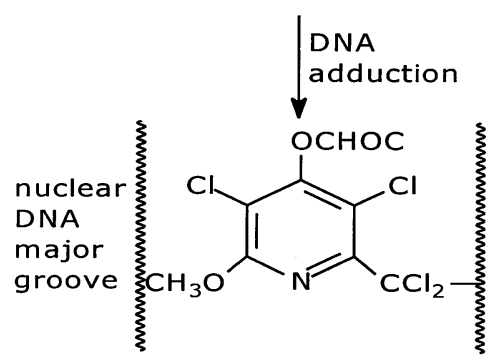

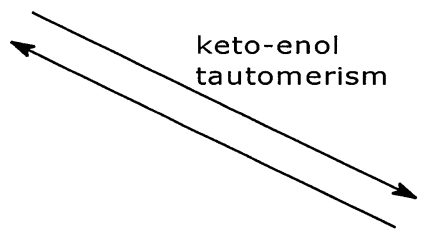<smiles>COc1nc(Cl)c(Cl)c(O)c1Cl</smiles>

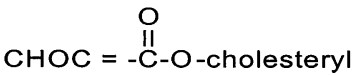

Fig. 4 Proposed mechanism of action of 4-demethyl-4-cholesterol-penclomedine (DM-CHOC-PEN)

blood-brain barrier and the IC activity reported in this paper [17].

The carbamate derivatives described were not as active versus the intracranially growing tumors as were the carbonates. Although the two functional groups such as carbamates and carbonates are considered to be chemically isosteric, the availability of a pair of $2 p$-electrons in the former actually increases the ease of protonization, reducing their ability to cross blood-brain barriers versus the carbonates [19].

Thus, DM-CHOC-PEN could be administered in combination with many of the clinically significant DNA major groove-alkylating drugs, that include methylating agents [e.g. dacarbazine and temozolomide (Temodar)] and chloroethylating agents [e.g. bis(chloroethyl)nitrosourea (BCNU) and clomesone], all of which form carbonium ionmediated DNA adducts via $\mathrm{O}^{6}$-guanine [18].
In summary, the anticancer activities observed for the carbonate and carbamate derivatives of DM-PEN, described with U251/D54 gliomas and MX-1 breast tumor implanted intracranially, identify these two classes of derivatives of DM-PEN as potential candidates for clinical development. The preclinical pharmacology, behavioral pharmacology and toxicology for DM-CHOC-PEN have been completed and will be presented in a paper with complete pharmacology, pharmacokinetic analysis and toxicology in mice, rats and dogs [20].

Acknowledgment The project was supported by grants from the National Cancer Institute's SBIR program-R43/44 CA85021.

Open Access This article is distributed under the terms of the Creative Commons Attribution Noncommercial License which permits any noncommercial use, distribution, and reproduction in any medium, provided the original author(s) and source are credited. 


\section{References}

1. Berlin J, Stewart JA, Storer B, Tutsch KD, Arzoomanian RZ, Alberti D, Feierabend C, Simon K, Wilding G (1998) Phase I clinical and pharmacokinetic trial of penclomedine using a novel, two stage trial design for patients with advanced malignancy. J Clin Oncol 16:1142-1149

2. O'Reilly S, Grochow L, Donehower RC, Bowling K, Chen TL, Hartman N, Struck R, Rowinsky EK (1997) Phase I and pharmacologic studies of penclomedine, a novel alkylating agent in patients with solid tumors. J Clin Oncol 15:1974-1984

3. Jodrell DI, Bowman A, Stewart M, Dunlop N, French R, MacLellan A, Cummings J, Smyth JF (1998) Dose-limiting neurotoxicity in a phase I study of penclomedine (NSC 388720, CRC 88-04), a synthetic alpha-picoline derivative, administered intravenously. Br J Cancer 77:808-811

4. Berlin J, Wahamaki A, Tutsch KD, Alberti D, Feierabend C, Binger K, Arzoomanian RZ, Volkman J, Karca J, Mornocha R, Stewart J, Wilding G (1999) Phase I, pharmacokinetic and bioavailability study of oral penclomedine administered daily $\times 5$ every four weeks. Proc Am Assoc Cancer Res 40:92

5. Hartman NR, O'Reilly S, Rowinsky EK, Collins JM, Strong JM (1996) Murine and human in vivo penclomedine metabolism. Clin Cancer Res 2:953-962

6. Plowman J, Harrison SD Jr, Dykes DJ, Paull KD, Narayanan VL, Tobol HK, Martin J, Griswold DP Jr (1989) Preclinical antitumor activity of an alpha-picoline derivative, penclomedine (NSC 338720), on human and murine tumors. Cancer Res 49:1909-1915

7. Harrison SD Jr, Plowman J, Dykes DJ, Waud WR, Griswold DP Jr (1991) Preclinical antitumor activity of penclomedine in mice: cross-resistance, schedule-dependence, and oral activity against tumor xenografts in brain. Cancer Res 51:1979-1985

8. O'Reilly S, Hartman NR, Grossman SA, Strong JM, Struck RF, Eller S, Lesser GJ, Donehower RC, Rowinsky EK (1996) Tissue and tumor distribution of ${ }^{14} \mathrm{C}$-penclomedine in rats. Clin Cancer Res 2:541-548

9. Reid JM, Mathieson DA, Benson LM, Kuffel MJ, Ames MM (1992) Murine pharmacokinetics and metabolism of penclomedine. Cancer Res 52:2830-2834
10. Waud WR, Tiwari A, Schmid SM, Shih T-W, Strong JM, Hartman NR, O'Reilly S, Struck RF (1997) 4-Demethylpenclomedine, an antitumor-active, potentially nonneurotoxic metabolite of penclomedine. Cancer Res 57:815-817

11. O'Reilly S, O'Hearn E, Rowinsky EK, Struck RF, Molliver ME (1996) Neuroanatomic studies of the cerebellar effects of penclomedine. Proc Am Assoc Cancer Res 37:374-375

12. O'Reilly S, O' Hearn E, Struck RF, Rowinsky EK, Molliver ME (2003) The alkylating agent penclomedine induces degeneration of purkinje cells in the rat cerebellum. Invest New Drugs 21:269

13. Friedman H, Keir S, Bigner D, Struck R (1998) Treatment of CNS tumor xenografts with penclomedine (PEN) and 4-demethylpenclomedine (4-DM-PEN). Proc Am Assoc Cancer Res 39:218

14. Morgan LR, Struck RF, Rodgers AH, Serota DG (2007) Preclinical toxicity of 4-demethylcholesteryloxylcarbonylpenclomedine (DM-CHOC-PEN). Proc Am Assoc Cancer Res 48:5614

15. Struck RF, Tiwari A, Friedman HS, Keir S, Morgan LR, Waud WR (2001) Acyl derivatives of demethylpenclomedine, an antitumor active, non-neurotoxic metabolite of penclomedine. Cancer Chemother Pharmacol 48:47-52

16. Struck RF, Waud WR (2006) Thiolo-, thiono- and dithiocarbonate and thiocarbamate derivatives of 4-demethylpenclomedine as novel anticancer agents. Cancer Chemother Pharmacol 48:180-184

17. Morgan LR, Struck RF, Waud W, Jursic BS, Serota DG, Papagiannis C, Rodgers AH (2007) Carbonate and carbamate derivatives of 4-demethylpenclomedine as novel anticancer agents. Molecular targets and cancer therapeutics. Am Assoc Cancer Res 49:280

18. Pletsas D, Wheelhouse RT, Pletsa V, Nicolaou A, Jenkins TC, Bibby MC, Kytopoulas SA (2006) Polar, functionalized guanine$\mathrm{O}^{6}$ derivatives resistant to repair by $\mathrm{O}^{6}$-alkylguanine-DNA alkyltransferase: implications for the design of DNA-modifying drugs, Eur. J Med Chem 11:1-10

19. Holland WC (1964) Thermodynamics and the concept of free energy. In: Holland WC, Klein RL, Briggs AH (eds) Introduction to molecular pharmacology. Macmillan, New York, pp 119-125

20. Morgan LR, Struck RF, Waud W, Jursic BS, Serota DG, Papagiannis C, Rodgers AH, Thornton, ME, GS LaHoste. Preclinical pharmacology and toxicity of 4-demethyl-cholesteryloxylcarbonylpenclomedine (DM-CHOC-PEN) (in press) 